\title{
$\mathbf{G} \mathbf{O}|\mathbf{P}|$ \\ Member since 2018 JM13710
}

EUROPEAN SPATIAL RESEARCH AND POLICY

Volume 27

Number 1

http://dx.doi.org/10.18778/1231-1952.27.1.03

\author{
Hans-Joachim BÜRKNER* ${ }^{*}$ Bastian LANGE ${ }^{* *}$ iD
}

\section{NEW GEOGRAPHIES OF WORK: RE-SCALING MICRO-WORLDS}

\begin{abstract}
The recently emerging new types of collaborative work and unconventional workplaces indicate that shifting social and economic practices have odd spatial implications. The diversity of work, mostly based on hybrid social and economic logics, has brought forth a number of new contextualised spatial constructs in recent years: makerspaces, fab labs, open workshops, and co-working spaces now require detailed analytical reconstruction and conceptualisation. This article is a theoretical discussion of the nature of fluid and contingent spatialisation against the backdrop of binary explanatory categories (e.g. local-global; proximity-distance). Drawing upon modernised concepts of horizontal scaling, we propose a perspective on hybrid work which focuses on contingent multiple, multidirectional and temporal scalings created by a variety of users while developing their own micro-worlds of work.
\end{abstract}

Key words: scale, flat ontology, new work, alternative workplaces, collaboration, social innovation.

\section{INTRODUCTION}

Co-working spaces, fab labs, open creative labs, open workshops, repair cafés, and other forms of 'untypical' work have recently puzzled urban scholars and economic geographers. They seem to indicate that new types of collaborative and community-oriented work entail shifting social and economic practices. These practices, in turn, have odd spatial implications which become obvious through emerging alternative and 'diverse' places (Gibson-Graham, 2008; Lange and Bürkner, 2018; Brinks, 2019; Schmid, 2019a). In particular, their spatiality involves temporary scalings triggered by digital technologies and a new sense of locality. Heterogeneous as the socio-economic processes and their spatial connotations obviously are, scholars of human geography and urban planners have restricted themselves

\footnotetext{
* Hans-Joachim BÜRKNER, Leibniz Institute for Research on Society and Space, Flakenstr. 29-31, 15537 Erkner, Germany, e-mail: hans-joachim.buerkner@leibniz-irs.de

** Bastian LANGE, University of Leipzig, Institute of Geography, Johannisallee 19a, 04103 Leipzig, Germany, e-mail: bastian.lange@uni-leipzig.de, ORCID: https://orcid.org/0000-0003-3619-900X
} 
to casual empirical descriptions, rather than engaging in systematic conceptualisation. This paper therefore seeks to provide a theoretical perspective towards the socio-spatial and scalar aspects of the rise of the new micro-worlds of work which have begun to change urban and economic realities.

The complexity of the problem is twofold. On the one hand, new work is based on heterogeneous social innovations and community building which seem to have strong ties to urban spaces (Brinks, 2019; Fabbri and Charue-Duboc, 2013). It departs from formal understandings of ubiquitous wage-dependent labour as it emerges from locally situated small-scale freelance and entrepreneurial activities, as well as from everyday practices of repairing, tinkering, computerised prototyping, sharing, and other forms of degrowth activism (Krueger et al., 2018; Lange and Bürkner, 2018; Schmid, 2019b). On the other hand, such informal approaches to 'new' work challenge geographers' traditional understandings of the relevance of space and scale for social and economic change. The phenomena mentioned above require more upto-date conceptualisations of post-industrial and post-capitalist small-scale production, the utilisation of new technologies and alternative ways of 'doing economy' (Chatterton and Pusey, 2019). Practically speaking, an acute view is in demand on how economies are being reconfigured today under the impact of altered social practices. We need to understand how social needs are met and economy is practically 'done'. This will not only refine disciplinary representations of social and economic change. It will also allow policy makers to better understand the geographies of new work. Last but not least it will enable them to develop well-informed action plans that may support the emerging fields of various forms of economies in cities and regions.

\section{PLAN OF THE PAPER}

This paper aims to clarify the significance of scale within the proliferating contexts of spatialisation connected with new types of work. It starts with a brief review of existing academic literature on coworking spaces, open creative labs, and open workshops, identifying scholars accounts of the significance of space and scale (Section 4). It then proceeds to discuss the hitherto undertheorised implications of scale and procedures of scaling, as related to technology-informed types of what we call 'hybrid work' (Section 5). Common notions of formalised work are based on the stipulation of a particularly economic logic of work formation. They imply a sharp distinction between economic rationality and different kinds of social logics, most of which have an impact on everyday life and reproduction. Consequently, many social and economic studies suggest that socio-spatial constructs are based on a similarly distinguishable opposition of either social or economic rationalities. 
However, within the new areas of 'doing economy', such dynamism has come to blur, and sometimes even extinguish, former distinctions between the economic and the social, raising hopes for successful future conceptualisations of social production (i.e. non-profit or low-profit production for social purposes) and non-alienated (i.e. self-organised and exploitation-free) work (Chatterton and Pusey, 2019). Therefore, in Section 6 we introduce a heuristic concept of 'hybrid work'. It defines the categorical division between economically defined labour and socially motivated concrete work. On this basis it describes the effects of digitisation and technologically advanced communication on work, namely as factors of the juxtaposition, and of the blending, of the various social and economic elements of work.

By adding a virtual dimension to activities at a local level, digitisation imposes further elements of hybridity on time-space relationships involved in work. For example, a co-working space or a coffee shop where a peer group works on a joint project does not only incorporate the specific sociality of peers but also takes in social relations to members of a wider community available in digital networks. All of them have effects on work routines and possible economic outcomes.

We aim to demonstrate that hybridisation does not simply consist in a blurring of categories provoked by digitisation. It is rather a flowing recombination of heterogeneous social and economic elements which assumes a distinct quality of its own: It is by constant flows of hybridisation that such heterogeneous, event-driven, socially motivated and community-oriented forms of concrete work take on their specific, often locally situated, individuality.

\section{CONCEPTUAL CONTRIBUTIONS OF THE PAPER}

In this perspective, we contribute to the debate on work which formerly had been classified as 'untypical' or 'amateurish', however, now assumes a quality that reshuffles society and space in a bottom-up way. Our approach not only alludes to an already well-known phenomenon that has been addressed as 'third space', i.e. the generation of hybrid public places by internet-based communication (Soukup, 2006). What is even more important is that it - once again - disturbs our everyday and academic concepts of space. Hybrid work challenges the traditional understandings of what is 'local', 'global', 'virtual' or contingently situated 'in between'. It refers to scale and temporary processes of scaling without suggesting the existence of clear-cut or invariable scales.

Quite obviously, then, new work has unprecedented scalar implications. However, scale theory, as implemented in many models of economic and social geography, as well as in political theory, has rather limited explanatory capacity when confronted with the hybridisation of social and economic practices. Therefore, in Section 
6 we shortly discuss the limitations of conventional concepts based on the idea of scale hierarchies. Alternatively, we opt for a tailored implementation of the 'flat ontology' approach to scale, as initially presented by Marston (2000) and Marston et al. (2005). In particular, we postulate to give up the idea of pre-fixed scales in favour of the temporal, event-driven creation and alteration of scales according to the needs of individual and collective actors, their particular ways of interacting and the challenges they meet. We then proceed to propose a concept of scaling which comes closer to the reality of emerging micro-worlds of work based on social innovation.

Finally, in Section 7 we will sketch how this reconceptualisation of scale might stimulate future research on micro-worlds of work. We assign the task of reconstructing the particular spatialities, created by new types of work, to an analytical perspective that seeks to identify multiple practices of open-ended scaling. By way of a careful ethnographic reconstruction of scaling practices that are salient within diverse work environments it will be possible in the future to paint a more differentiated picture of the scale implications of work. This task involves the demythologising of general categories, such as proximity/distance, which have so far dominated the debates in economic geography and the regional sciences on the social and economic construction of space.

\section{NEW WORK AS A TRIGGER OF NEW SPATIALITIES: STATE OF THE ART}

\subsection{Types of workplaces}

A small body of literature on neglected forms of 'diverse' economies, originating more than 10 years ago, has recently received new consideration (Gibson-Graham, 2008; Gibson-Graham et al., 2013). Its authors indicated the rather underrepresented status of reproductive work in academic literature on community economies, everyday informal production and other economic niches (especially Gibson-Graham, 2008). Moreover, within the critical debate on the social effects of late capitalism, those various forms of work which complement industrial labour have often been left aside and denied more acknowledgement.

Recent technological advances, in particular internet-based community building, have brought new academic recognition to 'untypical' work, together with a search for apt conceptualisation. There has emerged an everyday world of informal, amateurish, hobbyist, semi-professional and small-scale entrepreneurial activities, spurred by digital communication and a commons-based sharing of knowledge. They have been addressed as a variety of heterogeneous activities that particularly equip economic niches but also generally deviate from the dogma of economic growth, as disseminated by neo-liberal policies. Informally institu- 
tionalised as maker spaces, open workshops, fab labs, co-working spaces, and other types of community-based small-scale undertakings (Budge, 2019), they have been increasingly raising the attention of academic scholars.

Looking closer at the scalar terminologies used to describe the forms of work involved, it can easily be demonstrated that new work leaves the organisational logic of industrial production and location building. Mainly located outside the scope of formal categories and taxonomies of industrial labour, new concrete work has proliferated 'on the ground', mostly within urban neighbourhoods, as well as within virtual worlds, as represented by activist homepages, the social networks of the internet, online chat forums, specialised blogs and other meeting places of online communities (Quan-Haase and Martin, 2013).

Informally organised work has given rise to 'alternative' places which embrace working communities as well as occasional users of open-access facilities. These places share the feature of low organisational complexity and profit-free or low-profit management, often done by knowledgeable peers. Table 1 summarises the key types of such places which over the past decade have proliferated within mostly urban settings.

Table 1. Typology of alternative workplaces

\begin{tabular}{|l|l|l|}
\hline \multicolumn{1}{|c|}{$\begin{array}{c}\text { Key types of } \\
\text { alternative workplaces }\end{array}$} & \multicolumn{1}{|c|}{$\begin{array}{c}\text { Practices of doing } \\
\text { and working }\end{array}$} & \multicolumn{1}{c|}{$\begin{array}{c}\text { Organisational } \\
\text { and spatial practices }\end{array}$} \\
\hline $\begin{array}{l}\text { Open Workshop } \\
\text { (e.g. metal, wood, } \\
\text { digital, clothes, mobility, } \\
\text { plastics and others) }\end{array}$ & $\begin{array}{l}\text { Testing, experimenting, } \\
\text { repairing, prototyping, as well } \\
\text { as socialising with peers }\end{array}$ & $\begin{array}{l}\text { Operating as private associations; } \\
\text { core peers manage these spaces; } \\
\text { changing types of community } \\
\text { building }\end{array}$ \\
\hline Repair Café & $\begin{array}{l}\text { Fixing and repairing of } \\
\text { everyday consumer goods } \\
\text { under tutelage of peers }\end{array}$ & $\begin{array}{l}\text { Fixed opening times; core group of } \\
\text { responsible peers; visitors of Repair } \\
\text { Cafés use the place on demand only }\end{array}$ \\
\hline Creative Lab & $\begin{array}{l}\text { Developing ideas, tools } \\
\text { and processes for creative } \\
\text { production; analogue and } \\
\text { digital segments }\end{array}$ & $\begin{array}{l}\text { Run by experienced and } \\
\text { responsible 'place holders'; } \\
\text { external users rent spaces for } \\
\text { temporary purposes }\end{array}$ \\
\hline Fab Lab & $\begin{array}{l}\text { Low key as well as high level } \\
\text { application of 3D printers, } \\
\text { laser cutters, and other digital } \\
\text { fabrication tools }\end{array}$ & $\begin{array}{l}\text { Volunteering experts in technical } \\
\text { handling oversee machine and tools } \\
\text { usage; clearly regulated door and } \\
\text { entrance policies }\end{array}$ \\
\hline Co-working Space & $\begin{array}{l}\text { Office-like spatial infrastructure } \\
\text { for individual and collective } \\
\text { work; mainly frequented by } \\
\text { freelancers and startups }\end{array}$ & $\begin{array}{l}\text { Open access for temporary or } \\
\text { regular use by individuals or } \\
\text { collectives; organised on basis of } \\
\text { low-profit rental services }\end{array}$ \\
\hline
\end{tabular}

Sources: Hielscher and Smith (2014); Kleibrink and Schmidt (2015); Durante and Turvani (2018); Lange and Bürkner (2018). 
Diverse as these workplaces may be in social, economic and structural terms, they have a number of traits in common which set them apart from formalised industrial workplaces and job settings: they do not follow rigid working time schemes (e.g. the famous nine-to-five model); they enable open access of interested individuals, be they professionals or 'amateurs'; they embrace a wide range of forms of institutionalisation, extensively covering informal approaches based on friendship and peer relationships; they are driven by key protagonists who tend to decline profit-making in favour of degrowth rationales and the fulfilment of social needs (Lange and Bürkner, 2018). These workplaces have proliferated over the past decade at a similar rate as debates on post-growth economies and degrowth philosophies gained momentum among European and Transatlantic communities of experts and scholars.

\subsection{Refined definitions: labour vs. work}

Because of the obvious opposition between industrial and post-growth types of work, we follow Chatterton and Pusey's suggestions to distinguish between abstract, system-conformal labour and concrete, systemically footloose work (Chatterton and Pusey, 2019, with reference to Holloway, 2010). This distinction is particularly important as many studies on new work have indulged in outspoken categorical fuzziness. Moreover, the various worlds of new work have raised the attention of urban and regional policy makers who want to make use of this 'humus' and are keen to explore open entries into new and evolving digital worlds of production, as provided by 3D laser printing, laser cutting, and computerised prototyping. They begin to acknowledge the achievements of communities of crafts-oriented repairers, tinkerers, amateur designers, pro-ams ('professional amateurs') and prosumers (Grabher and Ibert, 2018). To distinguish between labour and work will help political actors to remember the different ideological starting points and the planning implications of industrial and 'alternative' activities more easily.

Such awareness becomes increasingly important as politicians have started to identify potential points of departure of post-growth infrastructures and supply, hoping that these might serve as substitutes in the recent recession of formal industries and services which followed policies of austerity (Chatterton and Pusey, 2019). Such expectations have been particularly nourished by the contingent formation of user-driven local assemblages where physical and digital tools, work rooms, internet access, meeting places, and learning facilities are organised on a more or less private and neighbourhood-related basis (Lange and Bürkner, 2018). However, their capacity to generate unexpected effects and follow idiosyncratic rationales has so far baffled politics. Community-oriented practices and social motives helped many 'new workers' to resist political attempts to exploit their original achievements. Their obstinacy invites close-up inspection and demands respect of the social autonomy implied. 


\subsection{Social innovation and political work in post-capitalist and degrowth contexts}

While often claimed to be connected to political activism based on post-capitalist and degrowth values (Demaria et al., 2019), the general openness of these assemblages to the public nevertheless enables a variety of users to put their diverse orientations and motivations into practice. Emerging social demands for the collective organisation of experimenting, learning, and processing materials are thus strongly supported by bottom-up social innovation, i.e. new practices, values, and norms that are gradually accepted and promoted by a given community of users (Smith, 2017).

Such socially situated innovation (Demaria et al., 2019) has been seminal to nascent micro-worlds of concrete work. At first sight these micro-worlds seem to be local phenomena, occasionally supplemented by a virtual world that individual users avail themselves of on demand. However, there is a more complex intertwining of heterogeneous elements involved, i.e. of individual actors, their social and work-induced relations, emerging networks and communities, data streams, knowledge produced and acquired, moods and atmospheres created, and symbols communicated. They are moulded and temporally fixed ('localised') at different places, levels, scales, transgressive spheres of transition and passage, or other elements of heterogeneous and flexible spatialisation.

Initial attempts by policymakers and academic scholars to address these phenomena as an original achievement of local actors, complemented by virtualised add-ons, quickly produced new urban myths. It was all too tempting for politicians to tell stories of the 'self-healing forces of the local neighbourhood', not without nurturing hopes for binding new - probably productive and wealth-producing - actors to urban localities that were facing new crises. After these neighbourhoods had been semantically conquered by Richard Florida's rhetoric of 'creative cities' 20 years ago (Florida, 2005), they are now prone to abandonment by the poorer part of the creative class (and other low-income groups) through the accelerated impact of powerful forms of financialisation, gentrification, and urban commodification. This holds true at least for the European contexts of urban development (McRobbie, 2015).

\subsection{Spatial proximity: the theorist's false friend}

Another potential factor in the creation of myths are scholarly convictions represented by well-established narratives of spatial proximity (Huber, 2012a; Martin et al., 2005). Regional sciences, urban studies, and economic geography have seen three decades of research on innovation regions, industrial clusters, branch networks, and creative economies where the category of the spatial proximity of important actors and institutions had been highlighted as key factors of explaining economic growth 
and future expectations for the viability of regions (e.g. Huber, 2012b). Such narratives of innovation-by-proximity, and also wealth-by-proximity, are now again found in connection with public conjectures on the significance of makerspaces, open creative labs, co-working spaces, community innovation labs, and their further derivates (Kleibrink and Schmidt, 2015). We are sceptical about such optimism and ask the focal question: Is the category of proximity plausible as an overall explanation of new work and its various economic and social implications, especially if these are embedded in post-growth milieus of practitioners?

For the time being, the answer still is ambiguous. Reading between the lines, the few empirical studies on work practices that characterise this new socio-economic field - situated between micro-entrepreneurialism and communitarian hobbyism - reveal that the category of proximity has a stake but does not explain for everything. Rather, there are indications of contingent and very flexible build-ups of multidirectional proximity-distance relations (Grabher and Ibert, 2018). Working 'on the ground' with traditional craft tools in a workbench fashion, while simultaneously applying digital tools, produces differential individual and collective 'attachments' to a workplace and surrounding communities of various composition (physical-local ones but also purely internet-based, hence virtual ones).

Moreover, important holders of expertise and knowledge may be locally co-present co-users and at the same time seemingly distant members of online communities. Conversely, even physically 'distant' actors may be very close to individual users, in fact closer than locally co-present partners might be, as they directly provide advice and disclose much of the intimate technical knowledge they command. They often also serve as important 'supra-local' or even cosmopolitan masterminds who influence local actors and activities. For example, many fab labs, open creative labs, and open workshops regularly communicate with expert members of online communities, including the US-based 'inventors' of the first makerspaces worldwide (Budge, 2019).

\subsection{Intermediate summary of the state of art and necessary of conceptual changes}

The flexibility, temporality, and intersecting nature of multiple, multidirectional and multiscale socio-spatial constructs requires careful analytical reconstruction and theory building. In particular, the simplistic proximity/distance theorems of the past must be overcome as they not only enticed scholars to disregard relational and scalar complexities in the field but also immediately led to several analytical pitfalls. Among the most important, we detected:

- Firstly, premature insisting on the relevance of space where the nature of work, i.e.specific relations of community, network and space, relations had been unclear (see e.g. Mack and Mayer, 2016); 
- Secondly, conceptual narrowness which marginalised non-physical (i.e. social, communicational, ideational, emotional) proximity/distance in favour of physical aspects (Liedke et al., 2015);

- Thirdly, a rather schematic juxtaposition of spatialised pairs of opposites (e.g. local/global) where it was clear that manifold interweavings between different spatial constructs and cross-level activities or phenomena had to be grasped (Graham et al., 2017);

- Fourthly, the tendency to assume a general spatialisation of social activities and relations, thus postulating an anthropological constant, whereas quite ostensibly digitisation and virtualisation implied the negation of space, if only partially or temporarily.

This short screening illustrates the urgent need to reconceptualise spatial relations and scales against the backdrop of accelerating digitisation and its impact on emerging new work. As we will discuss in Section 4, it will be expedient to adopt revised open scale models of the flat ontology type. Such models will have to refer to concrete work practices to evaluate their scope, flexibility, and shifting roots (e.g. those created by social innovation). From such a perspective, seemingly distinct 'spatial' levels will prove to reflect temporary situation-bound visions rather than solid ontological items.

Contingent and chaotic interconnections ascribed to some fixed 'ground level' can easily be rendered virtual or even fluid by considering the virtual (in older, reifying terms: 'global') spatialisations provided by digitisation and new community building. But before we delve deeper into these details, we here add some necessary remarks about the nature of hybrid work which has an effect on the scaling procedures occurring within these micro-worlds.

\section{HYBRID FORMS OF WORK: HARDLY ADDRESSABLE BY ABSTRACT CATEGORIES}

Until recently, studies on local and regional economies have focused on formalised and abstract types of work, generally referred to as 'labour'. Generalised economic understandings of work have even been applied within studies on urban creative industries which, paradoxically, had exposed the varieties, different origins and socio-spatial contexts of concrete work (Lange, 2011). Such negligence of the rich contextuality of work can be attributed to the underlying assumption that economic and social rationalities are basically separated.

This assumption has a long history in economic geography and the regional sciences. The social/economic divide theorem had mainly been popularised by using the narrative of the 'social embeddedness' of particular economies. It was 
introduced into economic literature by Granovetter (1985), then adopted by the proponents of relational economic geography (Bathelt and Glückler, 2003), and recently critically revised by McKeever, Anderson and Jack (2010). The basic idea follows the logical pattern of exceptionalism: the economy has a rationality of its own that is exceptionally altered by social or political practices. These practices can be either supportive or hindering; in the case of successful economies they have a supportive effect. Cross-cutting categories such as spatial (i.e. physical) proximity/distance, social proximity/distance or global/local interplay have contributed to the repeated reproduction of this conceptual pattern. The social/ economic divide of rationalities is supported by suggesting either the economic necessity of (mostly spatial) proximity, as e.g. implemented in cluster models (see Porter, 1998), or the occasional intrusion of the socio-spatial nearness of actors (e.g. through social milieus, clubs, peer groups or cliques) into economic fields, as represented in various concepts of a culturalised economy (McRobbie, 2015).

The practice of imagining social procedures as having exceptional or disturbing effects on the economy had a streamlining effect on economic model building. It allowed scholars to keep economic categories from becoming 'contaminated' by too many social connotations. As a consequence, the usage of 'labour' and abstract understandings of work continued to prevail. In contrast, concrete work, with its close factual links to everyday life, has been kept at a distance from theory building. In particular, the theoretical concepts of local or regional economic innovation and cluster building have extensively neglected the dynamic characteristics of heterogeneous, event-driven, socially motivated, 'atypical' or non-classified work (Avdikos and Kalogeresis, 2016).

Important steps towards acknowledging concrete practices and forms of work included the introduction of the concept of diverse economies with its focus on reproductive work (Gibson-Graham, 2008), and the recent approaches to alternative economies (Krüger, Schulz and Gibbs, 2018) that addressed more varieties of atypical work. However, these steps hardly incorporated the recent impact of new technologies on various actors and institutions. In effect, during the past 20 years digitisation and technologically advanced communication have rendered former divisions between social and economic rationalities increasingly questionable. In particular, they have begun to blur the formerly rigid roles of producers and consumers, inextricably integrating everyday life and its values into small-scale economies (Grabher and Ibert, 2018).

Therefore, the basic elements of work might still be addressed as 'social' and 'economic' but they actually coexist and interact so that they can often hardly be told apart. They are part of a particular hybridity which has to be taken into account when theorising small-scale activities placed against diversified backgrounds of digitisation and virtualisation (Moriset, 2013). Social and economic ends might be pursued by one and the same individual while being involved in one and the same process of work. We posit that such hybridisation is non-static 
and not necessarily 'bound to ground' but, on the contrary, explainable beyond the idea of a spatial fix which is favoured by former spatial theories. While the spatial fix has been conceived as an inevitable spatialization of economic mechanisms, as critically described by Faulconbridge (2006), the idea of hybridisation escapes this economic determinism by demanding heterogeneous causation. Hybridity thus evolves according to the social relations, ideas, communications, and technological tools utilised by relevant actors within open fields of 'doing economy'. The motivations, intentions, and achievements of those who work may tremendously differ according to social and economic contexts. They may shift from one situation to another, and so do related spatial constructs and their implications for social practices.

There is still another type of hybridisation introduced by digitisation and internet-based communication. Hybrid work, as defined above, is facilitated by digitisation because the former confinements of workplaces are either relativised or becoming obsolete. The 'local' worker always has a world-wide virtual space on standby. What they have produced can be made visible to global communities within seconds, and the responses to 'work in progress' can be incorporated from any non-local fields immediately. Hybrid communication, combining on-theground and face-to-face interaction with internet communication, partially liberates individuals from fixed socio-spatial environments such as neighbourhoods or local clubs. It introduces social experience and knowledge gained elsewhere and promotes reflections about social practices at a local level (Reckwitz, 2006).

Moreover, we are aware that within diverging fields of nascent hybrid work, progressing digitisation and the co-evolution of local and virtual networking (including community building of various types) blend, but also diversify and intersect, producing effects on scale building. For example, the user of a local open workshop who is involved in digital prototyping through $3 \mathrm{D}$ printing might get some advice from members of an online forum which momentarily opens his personal scaling to a particular global niche made up of peers. They deliberately open 'their' local space to a limited virtual space 'out there', taking their everyday set of internalised norms, conventions, and rules of conduct into a sphere of open and only weakly regulated communication. They might especially appreciate the warm atmosphere and the sensitive way of responding to the practical concerns that they express when reporting about their work. Hereafter this person might also address members of an open access online community to get some general information about the technical aspects of the workpiece they are creating, suspending the more socially motivated connection to the former forum members in favour of new information of a technical or economically relevant nature.

Another scaling may be enacted side by side with the formerly socially motivated one. Both of them might impact back on the local home base of our worker, e.g. in the course of the improvement they make in the technical handling of 
individual procedures of prototyping, and at the same time in communicating to their local peers about the changes they made. Scalings of different extension and impact are established on a temporal basis which are brought together upon a specific occasion (e.g. the need to gain knowledge or communicate one's experience).

For an empirical analysis, as well as for conceptualisation, the crucial point is the problem that it cannot be predicted how the two different scalings will occasionally combine to produce something unforeseen. Moreover, it will have to be determined in each case how and in what way individual scalings will have an effect and how strong this effect on social practices and economic relations will actually be.

Suitable theoretical tools to meet this challenge are rare. Earlier attempts to categorise scalings and their effects have often remained abstract and taxonomic (e.g. Pratt, 2013). They tacitly replicated the 'global-local interplay' theorem which had been generally ascribed to the post-modern network society (cf. Castells, 2010) while underrating the contingencies involved in concrete social practices. While the notion of 'interplay' suggests a fair amount of variability, the category itself hardly ever refers to social practice. In particular, there has been a considerable lack in the consideration of serendipity, especially when identifying the field-specific ways in which spatial relations and different horizons of flexible activities are construed.

Explicit consideration of the indeterminate, context-dependent qualities of hybrid work leads us to a better conceptualisation of the situated the origins of spatial relationships. Hybrid work has to be regarded as a generator of quickly shifting points of departure of temporary spatial constructs, rather than providing stable and geographically fixed socio-spatial relations. This perspective has already been mirrored by the flat ontology approach of the scale theory that we consequently adopt to clarify the spatial implications of hybrid work.

\section{FLAT ONTOLOGY APPROACHES TO SCALE THEORY AND THEIR RELEVANCE}

\subsection{Scale and its spatiality}

Traditional understandings of scale as spatially nested hierarchy have been repeatedly criticised for being static, reifying and under-complex (Moore, 2008; MacKinnon, 2011). In their perspectives, recent innovation practices and new work might only be addressed as relations and routines which 'span' or 'cross' pre-fixed local, global and other levels. They might at most be imagined as being involved in 'scale jumping' (Herod and Wright, 2002) or 'scale bending', the latter denoting the multidimensional restructuring of spatial scales through the inter- 
woven fields of activities and the temporary variations of the reaches of individual activities (Smith, 2004).

For example, a local stakeholder might address a specific problem through cooperation with a globally active organisation that helps disseminate locally raised issues on a world-wide scale. Such bending of normally fixed scales usually refers to political or institutional strategies. It hardly accounts for micro-processes of leaving, re-joining and finally blending scales in the course of everyday work that individuals and communities perform within technologically advanced environments.

However, this is exactly the key process that must be addressed, i.e. flexibly changing open scaling, as performed by individuals who communicate face-toface within a local frame, join online forums and networks a few minutes later, present a blog text to a world-wide audience and send e-mails or tweets to friends and colleagues working next door.

Such flexible scaling is basically 'flat' or non-hierarchical in the sense proposed by Marston et al. (2005) since it takes the social relations and interactions as points of departure for the incremental construction of scalar relationships. Relevant interactions can easily be observed in practices that individuals develop when they are exposed to the everyday impact of digitisation and globalisation. Bridging situations and contexts that are nearby and very distant at the same time bears signs of what has been coined before as 'time-space compression' (Harvey, 1989) but now clearly exceeds such abstract notions by its mere everyday multi-referentiality. Scaling is now woven into the fabric of what people actually do as situated actors who operate inside a digitised cosmos of everyday life. It instantly binds together what had been separated by another situation or context. It allows actors to deliberately refer to shifting social spheres and partners without having to leave the situation.

\subsection{Multiple forms of fluid scales}

It is all there at the same time, ready for use, regardless if it is physically available next door, through an online database or a virtual social network. Temporary scalings by individuals and collectives assume a multiple, multidirectional and heterogeneous nature. This tremendous multiplication of cross-referentiality has unprecedented technological underpinnings: for the most part, it draws on the exponential acceleration of communication speed through optical transmission (light-wave cables, satellite-based wireless transmission) and the high switching capability of the internet that promises to temporally synchronise social relations, ideas, activities, and material conditions.

Early calls for detailed analysis and open conceptualisiation of the processual aspects of scales in terms of 'everyday scaling' (Moore, 2008) and 'scalar politics' (MacKinnon, 2011) did not elaborate on digitisation as a driving force and a tool of scaling. These scholars nevertheless prepared the analytical ground, even 
though they had to realize that they did not find much resonance in coeval research communities of the political sciences where the problems of scale had originally been debated.

With the recent public and scholarly recognition of nascent practices of actors who are involved in the everyday flux of scaling and rescaling, especially of moving through nearby and distant physical, social, and virtual spaces, the question of how scales emerge can now be raised again in a more focused way. Apt concepts may address multiple individual and collective scalings which involve crisscrossed, circumvented or 'turned on and off' scales that are temporarily developed. In the particular case of makerspaces and labs such temporality is created according to incidentally arising necessities felt and debated within a particular community of actors who avail themselves of digital tools.

The potential applicability of such a perspective might be illustrated by simple everyday observations. For example, it is obvious that the particular fluidity of scaling and scale relations, as effected or influenced by digitisation, has already changed work practices in the mainstream economy and the related communication in everyday life. Digitisation and the top-down reorganisation of unqualified work within the platform-based gig economy have not only affected the procedures and social environments of work; they have also changed workers' job market competitiveness (Graham et al., 2017), i.e. from managing personalised worker-employer relationships to status seeking within the opaque hierarchies of automatically assessed micro-workers. Different scalings may serve to interrelate these seemingly unrelated spheres to keep individuals competitive and motivated. Of course, this is a neo-liberal scenery of scaling triggered by digitisation, but similar degrees of fluidity can be assumed for post-growth sceneries as well.

\subsection{Flat ontologies}

By virtually adding next-door competitors and collaborators who may in fact be located in the global South, former scale relations have been rendered obsolete on a day-to-day basis. This is not a mere process of delimitation which had been identified as a core process of globalisation by its early theorists (e.g. Castells, 2000). Rather, it is a chaotic, individualised, and technology-bound delimitation which has to be specified in order to become theoretically relevant. It is new hybrid work in particular which has brought specific ways of the reshuffling and liquefaction of scales to an extreme, as it continually multiplies relevant social and spatial points of reference. Fab labs, makerspaces, open workshops, and co-working spaces represent micro-worlds of work with oscillating situational and temporary scale relations. By imagining scaling as an ever-changing social phenomenon created and revised on an everyday basis it can be expected that analysis will move closer to the reality of the micro-worlds of heterogeneous work. 
The existing scale concepts which have already begun to address flexible and shifting scaling promise to provide at least some points of departure for identifying the scalar relationships that characterise the socio-economic fields of new work. The notion of flat ontologies, as introduced by Marston (Marston, 2000; Marston et al., 2005), does not only imply horizontal relationships and communication between individuals but also applies to reconfigurations between actors, institutions and material elements involved. This point has been emphasised by Farias, an actor-network theorist, when he stated that concrete actors and contexts shape multiple instances of space, scale and time which are assembled at concrete local sites (Farias, 2010, p. 6).

While there is some danger of marginalising the existence of vertical social relationships, hierarchies and power relations (cf. related criticism by Leitner and Miller, 2007), particular sensitiveness towards the issues of power can be easily incorporated into open scaling concepts. For example, it can be acknowledged that even decidedly 'flat' configurations of actors within an assemblage, even those in the fashion of fab labs and makerspaces that are expected to 'democratise' access to advanced technologies (Schneider and Lösch, 2019), still have their small organisational elites or knowledge elites that capitalise on their ascribed roles as informal teachers and advisors of users (Bürkner and Lange, 2016, p. 313).

The question about the modifications and corrections which will have to be made to grasp the specificities of recently evolving micro-worlds characterised by hybrid work, especially under conditions of digitisation and virtualisation, will be crucial for the applicability of such an approach. More precisely, it will be important to identify and interpret the 'vertical excursions' along established or emerging hierarchies that everyday actors individually or collectively perform - locally and, at the same time, throughout virtual communities.

\section{SCALAR RELATIONS WITHIN NEW MICRO-WORLDS OF WORK}

\subsection{Applying flat ontologies to new forms of work}

Two basic procedures are required to apply the perspective of flat ontologies: firstly, identify in detail the various directions and extents of movements that individuals and collectives perform while being involved in practices of hybrid work and the proliferation of its varieties; and, secondly, to establish a critical perspective on the locale, in particular on urban localities, as a point of conceptualisation where older myths of proximity are increasingly challenged by various expectations of multiple rescaling. 
The first procedure can best be implemented by focusing on particular activities unfolded by users of fab labs, open workshops, and makerspaces. For example, social practices such as sharing or the non-profit exchange of material and immaterial goods (among others, lenging teaching assistance and doing favours), often unfold via the internet. Users may prefer informal types of communication (chatrooms, forums); they may also make use of more formally organised platforms and applications, including social media outlets such as Facebook.

In this way, if the member of an open workshop in Berlin puts a very simple question of the type "Has anyone got an idea how I might make my $3 D$ printer produce the structure that you see on the picture I posted?", they will receive answers from people that may be close in social terms, because the user already knows the respondents very well, and at the same time geographically very distant because the respondent lives in, say, Taiwan. Using virtual communities as suppliers of innovative ideas may be something that involves the global sphere, but it might also be restricted to a 'circle' of friends and communication partners living in the same town or region but interacting through the internet.

Flat ontologies of this sort are dynamic and volatile. A simple act of 'flat' communication with peers creates several horizontal axes through a virtual space, at least as long as there is no social differentiation established between the peers. However, as soon as one respondent begins to hold specialised knowledge that they capitalise upon, or holds a well-respected position within an online community (e.g. one organised by the inventors of the first makerspaces), an element of hierarchy emerges which criss-crosses the idea of pure horizontality.

A similar level-up extension of an axis occurs if the locality of a user is known to others and prompts them to express respect or admiration. For example, the peer from Taiwan might say that they were wondering why they were asked for advice because open workshops in Berlin would rank as a global avant-garde. This symbolic valuing of a place refers to place hierarchies already established outside the internet but being reproduced and traded there. Since the online peer usually does not know exactly about the social contexts that are connected to the place, they might also extend their admiration to the social community located there.

In summary, we may note complex, heterogeneous configurations of multiple coincident scaling involved in one simple act of communication that brings in aberrations from the 'horizontal' sphere assumed.

\subsection{Changed perspectives on flat connectivities}

To take the last example even further: A closely related process of scaling may be initiated if the user who asked the original question took the advice they received online to their workplace the next day. Although he personally did not care about reputation, the local peers who were present on that occasion might have referred 
to the Taiwan-based user as someone who commands advanced knowledge, introducing a personalised hierarchy of reputation to what might otherwise have been a plane of social equality.

It can easily be seen that flat ontology and formerly horizontal scalings respond to spontaneous suggestions to build hierarchies, at least for a limited time. At the same time, the concrete place 'on the ground' is reshaped. In our example, it is collectively construed as a striving locale hosting ambitious co-workers. A simple act of implementing new knowledge with a connotation of 'stepping up in the global hierarchy of knowledge holders' may thus contribute to the collective re-construction of space. Of course, this is not the only formative act that shapes a place; there may be other valuations made by face-to-face co-present users who appraise the tools, the social setting, the atmosphere and other features of the workplace.

In this way, the complex, intersecting and interweaving quality of scaling reveals itself as soon as it is explored in detail. Within the context of hybrid work, scaling must be understood as the outcome of flexible mental and communicative extensions of a workplace. Complexity might be further increased by the degree of economisation that users develop while experimenting with materials and communicating with peers. Some of them may be inspired to engage in computer-based prototyping, ending up with an idea for a marketable product. They might even plan to establish a start-up enterprise and formalise their activities, so that their work becomes more accountable to others. Finally, promises of continually delivering high-quality products might be made.

Such an upscaling of seminal economic concepts does not necessarily marginalise social rationalities, so that hybrid work might finally be abandoned. Rather, it may still interact with peers' expectations for grassroots experimenting, tinkering and sharing. It will temporarily produce vertical axes of scaling which intersect with more horizontal axes. These 'upward-bound' axes, geared towards a formalised mainstream economy, might diminish as soon as economic failure looms or factually happens.

They might nevertheless leave an imprint on the local community which suspects the want-to-be entrepreneur of betraying their degrowth aspirations. This, in turn, might affect the work practices and the future plans of the individual deviant.

\subsection{Local-global interplay of new forms of work}

This brings in the second, more critical procedure mentioned above. At first, the local place in question might appear as the breeding place of social innovation and unexpected social or economic initiatives and work routines. New local communities of tinkerers, 3D enthusiasts and sharing practitioners might appear as original creators of the locality. They seem to conform to the old idea of spatial proximity which stifles innovation, recently augmented by virtual communication and extended knowledge resources that help to furnish this particular place. 
However, the preceding consideration of concrete work practices and the manifold scaling processes involved have already indicated that there might be no unilateral or exclusively local construction of space at work. Adding to the collective desire to have a meeting place for like-minded informal workers, or a place where to acquire knowledge and proficiency, supra-local activities are always implicated. Local users are also globally floating internet users: on several occasions they act as setters of manifold and temporarily shifting touch-down areas of virtual networks and communities, regardless of whether they aware of it or not. They help to introduce 'external' ideas to a local level, e.g. ideas about profitless or profit-reduced work procedures which had formerly been debated online (but to a lesser extent also on the local ground).

Such place building is obviously based on heterogeneous social causation. It involves members of other societies, openly communicating within online communities, who are often unfamiliar with a place. It also incorporates members of one and the same domestic society who are newly aggregated through a particular community that is familiar with the place and its evolution. The place is assembled by a particular contingent logic which has been transformed by scaling before and continues to do so by freshly emerging activities. By the same token, it can have reciprocal effects: it might become visible as a trendy or avant-garde place which is taken as a matter of discourse and discussed by online communities around the world, with effects for other localities where hybrid work emerges.

\section{CONCLUSIONS}

Our theoretical explorations into 'doing work' and establishing new, hybrid forms of work have rendered flexible processes of scaling and re-scaling an important implication of nascent micro-worlds of work. These worlds can now be described more precisely by explicit consideration of the heterogeneous social and economic impulses incorporated into new work practices. Such impulses manifest themselves through multidirectional communication within a composite social, economic and virtual space. They are enacted by multiple, heterogeneous intersecting and blending scalings. At minimum, micro-worlds may be conceptualised as the outcome of a centrifugal movement originating from local (or localised) social communities that proceed in the direction of growing virtualisation and the creation of flexible touchdowns of virtual communities. But they may also be conceived the other way around, as the results of a centripetal movement through the local fixation of global online networks and other (seemingly external) networks. Both movements are interconnected through hybrid communication channels and types of sociality. They rely on the co-creation of heterogeneous social, technological (digital) and physical spaces. 
Future explorations into the nature of hybrid work and its spatial implications will have to shed more light on social innovations and the binding forces they create for the evolution of hybrid work. On the methodological side, this will require more ethnographical work than geographers or regional and urban scholars have probably been accustomed to. This is not an end in itself but rather something necessary due to the requirement to provide detailed analyses of emerging work forms and flexible scalings. Additionally, it will open up new interfaces to theories of social practice and revived debates on the culturalization of globalised economies.

\section{REFERENCES}

AVDIKOS, V. and KALOGERESIS, A. (2016), 'Socio-economic profile and working conditions of freelancers in co-working spaces and work collectives: evidence from the design sector in Greece', Area, 49 (1), pp. 35-42. https://doi.org/10.1111/area.12279

BATHELT, H. and GLÜCKLER, J. (2003), 'Toward a relational economic geography', Journal of Economic Geography, 3 (2), pp. 117-144. https://doi.org/10.1093/jeg/3.2.117

BRINKS, V. (2019), "«And Since I Knew About the Possibilities There ...»: The Role of Open Creative Labs in User Innovation Processes', Tijdschrift voor economische en sociale geografie, 110 (4), pp. 381-394. https://doi.org/10.1111/tesg.12353

BUDGE, K. (2019), 'The ecosystem of a makerspace: Human, material and place-based interrelationships', Journal of Design, Business \& Society, 5 (1), pp. 77-94. https://doi.org/10.1386/ dbs.5.1.77 1

BÜRKNER, H.-J. and LANGE, B. (2016), Configurations of Value Creation in Open Workshops, [in:] WULFSBERG, J.P., REDLICH, T. and MORITZ, M. (eds.), 1. interdisziplinäre Konferenz zur Zukunft der Wertschöpfung, Hamburg: Helmut-Schmidt-Universität, pp. 307-316.

CASTELLS, M. (2000), The Rise of the Network Society, Oxford: Blackwell Publishers.

CASTELLS, M. (2010), 'Globalisation, Networking, Urbanisation: Reflections on the Spatial Dynamics of the Information Age', Urban Studies, 47 (13), pp. 2737-2745. https://doi. org $110.1177 / 0042098010377365$

CHATTERTON, P. and PUSEY, A. (2019), 'Beyond capitalist enclosure, commodification and alienation: Postcapitalist praxis as commons, social production and useful doing', Progress in Human Geography, 44 (2). https://doi.org/10.1177/0309132518821173

DEMARIA, F., KALLIS, G. and BAKKER, K. (2019), 'Geographies of degrowth: Nowtopias, resurgences and the decolonization of imaginaries and places, ENE: Nature and Space, 2 (3), pp. 431-450. https://doi.org/10.1177/2514848619869689

DURANTE, G. and TURVANI, M. (2018), 'Coworking, the Sharing Economy, and the City: Which Role for the 'Coworking Entrepreneur'?', Urban Science, 2 (3), pp. 1-21, https://www.mdpi. com/2413-8851/2/3/83. https://doi.org/10.3390/urbansci2030083

FABBRI, J. and CHARUE-DUBOC, F. (2013), 'The Role of Physical Space in Collaborative Workplaces Hosting Entrepreneurs', [in:] VAUJANY, F.-X. and MITEV, N. (eds.), Materiality and Space: Organizations, Artefacts and Practices, Houndmills, Basingstoke, Hampshire: Springer, pp. 117-134. https://doi.org/10.1057/9781137304094.0015

FARIAS, I. (2010), 'Introduction: decentring the object of urban studies', [in:] FARIAS, I. and BENDER, T. (eds.), Urban assemblages: How actor-network theory changes urban studies, London, New York: Routledge, pp. 1-24. 
FAULCONBRIDGE, J.R. (2006), 'Stretching tacit knowledge beyond a local fix? Global spaces of learning in advertising professional service firms', Journal of Economic Geography, 6 (4), pp. 517-540. https://doi.org/10.1093/jeg/lbi023

FLORIDA, R. (2005), Cities and the creative class, New York: Routledge. https://doi. org/10.4324/9780203997673

GIBSON-GRAHAM, J.K. (2008), 'Diverse economies: performative practices for 'other worlds", Progress in Human Geography 32 (5), pp. 613-632. https://doi.org/10.1177/0309132508090821

GIBSON-GRAHAM, J.K., CAMERON, J. and HEALY, S. (2013), Take Back the Economy: An Ethical Guide for Transforming Our Communities, Minneapolis: University of Minnesota Press. https://doi.org/10.5749/minnesota/9780816676064.001.0001

GRABHER, G. and IBERT, O. (2018), 'Schumpeterian Customers? How Active Users Co-create Innovations', [in:] CLARK, G.L., FELDMAN, M.P., GERTLER, M.S. and WÓJCIK, D. (eds.), The New Oxford Handbook of Economic Geography, Oxford: Oxford University Press, pp. 286-304. https://doi.org/10.1093/oxfordhb/9780198755609.013.36

GRAHAM, M., HJORTH, I. and LEHDONVIRTA, V. (2017), 'Digital labour and development: impacts of global digital labour platforms and the gig economy on worker livelihoods', Transfer: European Review of Labour and Research, 23 (2), pp. 135-162. https://doi. org/10.1177/1024258916687250

GRANOVETTER, M. (1985), 'Economic Action and Social Structure: The Problem of Embeddedness', American Journal of Sociology, 91 (3), pp. 481-510. https://doi.org/10.1086/228311

HARVEY, D. (1989), The Condition of Modernity: An Enquiry into the Origins of Cultural Change, Oxford: Blackwell.

HEROD, A. and WRIGHT, M.W. (2002), 'Placing Scale: An Introduction', [in:] HEROD, A. and WRIGHT, M.W. (eds.), Geographies of Power: Placing Scale, Malden, MA: Blackwell, pp. 1-14. https://doi.org/10.1002/9780470773406.ch

HIELSCHER, S. and SMITH, A. (2014), 'Community-based digital fabrication workshops: A review of the research literature', Falmer: University of Sussex, SPRU Working Paper Series SWPS 2014-08. http://dx.doi.org/10.2139/ssrn.2742121.

HOLLOWAY, J. (2010), Crack Capitalism, London: Pluto Press.

HUBER, F. (2012a), 'On the Role and Interrelationship of Spatial, Social and Cognitive Proximity: Personal Knowledge Relationships of R\&D Workers in the Cambridge Information Technology Cluster', Regional Studies, 46 (9), pp. 1169-1182. https://doi.org/10.1080/00343404.2011.569 539

HUBER, F. (2012b), 'On the Role and Interrelationship of Spatial, Social and Cognitive Proximity: Personal Knowledge Relationships of R\&D Workers in the Cambridge Information Technology Cluster', Regional Studies, 46 (9), pp. 1169-1182. https://doi.org/10.1080/00343404.2011.569 539

KLEIBRINK, A. and SCHMIDT, S. (2015), 'Communities of Practice as New Actors: Innovation Labs Inside and Outside Government', [in:] European Commission (ed.), Open Innovation 2.0 Yearbook 2015, Luxemburg: Luxembourg Publication Office of the European Union, pp. 64-73.

KRUEGER, R., SCHULZ, C. and GIBBS, D. (2018), 'Institutionalizing alternative economic spaces? An interpretivist perspective on diverse economies', Progress in Human Geography, 42 (4), pp. 569-589. https://doi.org/10.1177/0309132517694530

LANGE, B. (2011), 'Accessing Markets in Creative Industries: Professionalisation and social-spatial strategies of Culturepreneurs in Berlin', Entrepreneurship and Regional Development, 23 (3), pp. 259-279.

LANGE, B. and BÜRKNER, H.-J. (2018), 'Open workshops as sites of innovative socio-economic practices: approaching urban post-growth by assemblage theory', Local Environment, 23 (7), pp. 680-696. https://doi.org/10.1080/13549839.2017.1418305 
LEITNER, H. and MILLER, B. (2007), 'Scale and the limitations of ontological debate: a commentary on Marston, Jones and Woodward', Transactions of the Institute of British Geographers, New Series, 32, pp. 116-125. https://doi.org/10.1111/j.1475-5661.2007.00236.x

LIEDTKE, C., BAEDEKER, C., HASSELKUß, M., ROHN, H. and GRINEWITSCHUS, V. (2015), 'User-integrated innovation in Sustainable LivingLabs: an experimental infrastructure for researching and developing sustainable product service systems', Journal of Cleaner Production, 97, pp. 106-116. https://doi.org/10.1016/j.jclepro.2014.04.070

MACK, E. and MAYER, H. (2016), 'The evolutionary dynamics of entrepreneurial ecosystems', Urban Studies, 53 (10), pp. 2118-2133. https://doi.org/10.1177/0042098015586547

MACKINNON, D. (2011), 'Reconstructing scale: Towards a new scalar politics', Progress in Human Geography, 35 (1), pp. 21-36. https://doi.org/10.1177/0309132510367841

MARSTON, S.A. (2000), 'The social construction of scale', Progress in Geography 24 (2), pp. 219 242. https://doi.org/10.1191/030913200674086272

MARSTON, S.A., JONES III, J.P. and WOODWARD, K. (2005), 'Human geography without scale', Transactions of the Institute of British Geographers, New Series, 30, pp. 416-432. https://doi.org/10.1111/j.1475-5661.2005.00180.x

MARTIN, R., BERNDT, C., KLAGGE, B. and SUNLEY, P. (2005), 'Spatial proximity effects and regional equity gaps in the venture capital market: Evidence from Germany and the United Kingdom', Environment and Planning, 37 (7), pp. 1207-1231. https://doi. org/10.1068/a3714

McKEEVER, E., ANDERSON, A. and JACK, S. (2014), 'Social embeddedness in entrepreneurship research: the importance of context and community', [in:] CHELL, E. and KARATAŞ-ÖZKAN, M. (eds.), Handbook of Research in Entrepreneurship and Small Business, Cheltenham, Northampton: Edward Elgar, pp. 222-236. https://doi.org/10.4337/9781849809245.00022

McROBBIE, A. (2015), Be Creative: Making a Living in the New Culture Industries, London: Polity Press.

MOORE, A. (2008), 'Rethinking scale as a geographical category: from analysis to practice', Progress in Human Geography, 32 (2), pp. 203-225. https://doi.org/10.1177/0309132507087647

MORISET, B. (2013), Building new places of the creative economy: The rise of coworking spaces, Utrecht: Utrecht University, https://halshs.archives-ouvertes.fr/halshs-00914075.

PORTER, M.E. (1998), 'Clusters and the new economics of competition', Harvard Business Review, 76 (6), pp. 77-90.

PRATT, A.C. (2013), 'Space and Place', [in:] TOWSE, R. and HANDKE, C. (eds.), Handbook on the Digital Creative Economy, Cheltenham: Edward Elgar, pp. 37-44. https://doi. org/10.4337/9781781004876.00013

QUAN-HAASE, A. and MARTIN, K. (2013), 'Digital curation and the networked audience of urban events: Expanding La Fiesta de Santo Toma's from the physical to the virtual environment', International Communication Gazette, 75 (1), pp. 521-537. https://doi. org/10.1177/1748048513491910

RECKWITZ, A. (2006), Das hybride Subjekt: eine Theorie der Subjektkulturen von der bürgerlichen Moderne zur Postmoderne, Weilerswist: Velbrück.

SCHMID, B. (2019a), 'Degrowth and postcapitalism: Transformative geographies beyond accumulation and growth', Geography Compass. https://oi.org/10.1111/gec3.12470

SCHMID, B. (2019b), 'Repair's diverse transformative geographies: lessons from a maker community in Stuttgart', Ephemera: Theory and Politics in Organization, 19 (2), pp. 229-251.

SCHNEIDER, C. and LÖSCH, A. (2019), 'Visions in assemblages: Future-making and governance in FabLabs', Futures, 109, pp. 203-212. https://doi.org/10.1016/j.futures.2018.08.003

SMITH, A. (2017), 'Social Innovation, Democracy and Makerspaces', Falmer: University of Sussex', SPRU Working Paper Series SWPS 2017-10. https://doi.org/10.2139/ssrn.2986245 
SMITH, N. (2002), 'Scale Bending and the Fate of the National', [in:] SHEPPARD, E.S. and MCMASTER, R.B. (eds.), Scale and geographic inquiry: Nature, society, and method, Malden, MA: Blackwell, pp. 192-212. https://doi.org/10.1002/9780470999141.ch10

SOUKUP, C. (2006), 'Computer-mediated communication as a virtual third place: building Oldenburg's great good places on the world wide web', New Media \& Society, 8 (3), pp. 421-440. https://doi.org/10.1177/1461444806061953 